\title{
Oral Characteristics of Trisomy 8 and Monosomy 18: A Case Report
}

\author{
Giovanni Spano $^{{ }^{*}}$, Silvana Sale ${ }^{1}$, Guglielmo Campus ${ }^{1}$ and Pierfranca Lugliè ${ }^{1}$ \\ ${ }^{I}$ Dental School, School of Dentistry, University of Sassari, Italy
}

\begin{abstract}
Several reports described various mosaic chromosomal syndromes characterized by alterations originated by either an excess or deficit in the number of chromosomes. A case of mosaic trisomy 8 and monosomy 18 with significant involvement of the oral cavity is described, both in terms of general medicine and from a dental-oral perspective, and the treatment plan was planned and discussed.

Regular follow-up visits enabled to verify significant improvement in all parameters of the patient's oral health, which urged us to press on with our quest to protect the right to health of patients affected by disabilities.
\end{abstract}

Keywords: Chromosomal syndromes, oral health, disabled patients.

\section{INTRODUCTION}

Several mosaic chromosomal syndromes are characterized by alterations caused by either an excess or deficit of two or more chromosomes. Many anomalies have been associated with several syndromes: growth deficits, mental retardation, motor difficulties, microencephaly, agenesis of the corpus callosum, heart defects, low-set, malformed ears, hypertelorism, snub nose, and very low-set hairline. Furthermore, serious alterations have been reported in oral cavity of these patients, including cleft lip and palate, high-arched (ogival) palate, anterior open-bite and small jaw (micrognathia), and, in one reviewed case, taurodontism [1-6]. A comprehensive table of the main features (general and oral) of chromosomial anomalies is displayed in Table $\mathbf{1}$.

\section{AIM}

The purpose of this case-report is to describe the dental and oral situation of a young patient affected by a rare chromosomal disorder (trisomy of chromosome 8 and monosomy of chromosome 18 mosaic) previously unreported in literature and to illustrate the treatment plan.

\section{Case Description}

The patient, male aged 12-year-olds, arrived at the Dental Clinic of the University of Sassari taken by his mother. She reported that, the children experienced discomfort when ingesting food and liquids, and that he had several caries lesions.

The medical history of the patients pointed out a complex clinical picture. Moreover, the young patient was completely uncooperative and persisted on keeping his mp3 headphones on; his mother indicated this was the only way to "keep him quiet and calm".

*Address correspondence to this author at the Dental Institute, University of Sassari Viale S. Pietro 4307100 Sassari, Italy; Tel +39 079 228572;

Fax: +39079 228541; E-mail: giove67@yahoo.it

\section{General Medical History}

The medical history together the documents provided by the mother indicated that the patient is the third-born child in his family, with two older brothers. Both parents and siblings are in apparent good health. The child was conceived when his father was 31 and his mother 24. In consideration of his malformations, previously diagnosed via ultrasound scan a Caesarean-section was performed at 40 weeks gestation.

The mother's pregnancy had presented no noteworthy complications. At birth the patient showed: dysmorphic $f a-$ cies with brachycephaly, low forehead with low-set hairline on the forehead, short eyelid rims with slightly mongoloid attitude, esotropia, and hypertelorism. Furthermore, in the patient were observed evident manifestations of unilateral complete cleft of left primary and secondary palate, ipomaxilla, low-set ears with flattened and slightly pointed helixes, prominent antitragi with wide and stubby lobules and short and webbed neck. Several other anomalies were also present in both upper and lower limbs and in the external genitalia.

Echoencephalogram revealed agenesis of the corpus callosum with colpocephaly and ultrasound scan of the kidneys evidenced first degree, right side pyelectasis.

At the age of two, the patient was referred for genetic analysis (Regional Center for the Ente Ospedaliero Ospedali Galliera in Genoa), where an in-situ hybridization test was performed on lymphocyte metaphases from peripheral blood.

The results evidenced a two cell-line karyotype with reciprocal translocation between a chromosome 8 and a chromosome 18:

$(46, \mathrm{xy}, \mathrm{t}(8 ; 18)(8 \mathrm{qter} \rightarrow 8 \mathrm{p} 21.1:: 18 \mathrm{q} 23 \rightarrow 18 \mathrm{pter} \rightarrow 18 \mathrm{q} 23:: 8$ p21 $\rightarrow 8$ pter//.46,xy,t( $8 ; 18)(8 \mathrm{qter} \rightarrow 8 \mathrm{p} 21.1:: 18 \mathrm{q} 23:: 18 \mathrm{qter} \rightarrow 1$ $8 q 23:: 8$ p21.1 $\rightarrow 8$ qter; 8 pter $\rightarrow 18 q 23:: 8$ p21.1 $\rightarrow$ 8pter.

It was not until 2000 , that the presence of transmissive hypoacusia and epilepsy were also revealed, as well as subvalvular aortic stenosis (corrective surgery was performed in 
Table 1. Main Features (General Medical and Head-Neck and Oral) of the Case Described in this Paper and Comparison of Other Chromosomial Anomalies

\begin{tabular}{|c|c|c|c|c|c|}
\hline & $\begin{array}{c}\text { Trisomy } 8 \\
\text { Monosomy } 1^{2}\end{array}$ & Trisomy $18^{1-5}$ & $\begin{array}{c}\text { Trisomy } 8 \\
\text { Mosaicism }^{2}\end{array}$ & Trisomy 9 Mosaicism ${ }^{5}$ & $\begin{array}{c}\text { Trisomy } 20 \\
\text { Monosomy } 11^{3}\end{array}$ \\
\hline \multicolumn{6}{|c|}{ General Medical features } \\
\hline Malformed ears & + & + & + & + & + \\
\hline Ocular anomalies & + & + & + & + & + \\
\hline Hypertelorism & + & $+(33 \%$ cases $)$ & + & - & + \\
\hline Webbed neck & + & + & - & - & - \\
\hline Upper limbs anomalies & + & + & + & - & - \\
\hline Lower limbs anomalies & + & + & - & + & - \\
\hline Urogenital anomalies & + & $+(33 \%$ cases $)$ & + & - & + \\
\hline Kidney's anomalies & + & - & + & + & + \\
\hline Nervous central anomalies & + & + & + & + & + \\
\hline \multicolumn{6}{|c|}{ Head-neck Oral features } \\
\hline Cleft-palate & + & - & + & - & - \\
\hline Prognathism & + (mandibular) & + (maxillar) & $+($ micrognatia $)$ & + (maxillar) & - \\
\hline Open bite & + & - & - & - & - \\
\hline Ankjloglossia & + & - & - & - & - \\
\hline Narrow high-arced palate & - & - & + & + & - \\
\hline
\end{tabular}

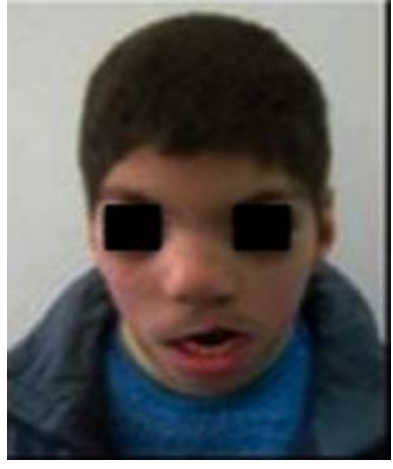

Fig. (1). Frontal view of the patient.

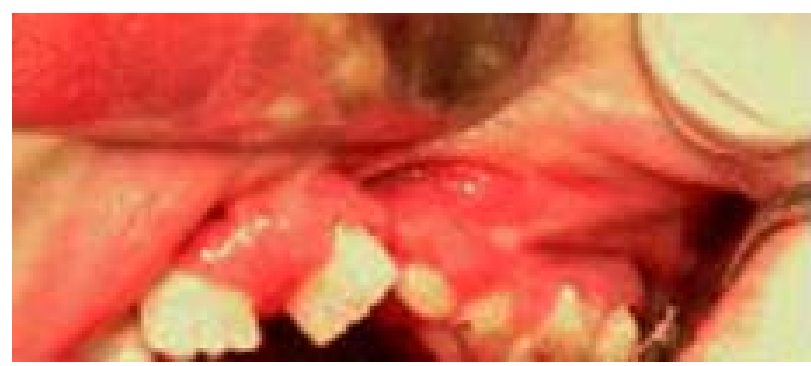

Fig. (2). Sequela of cleft upper lip cicatrisation.

2001), gastroesophageal reflux, and severe psico-motor retardation.

\section{Oral Examination}

The complete lack of patient's cooperation made the intra-oral examination extremely tough to perform. An examination of the patient's face evidenced prognathism of the lower jaw, labial incompetence with sequela of cleft upper lip cicatrisation, a significant anterior open-bite, hyperte-

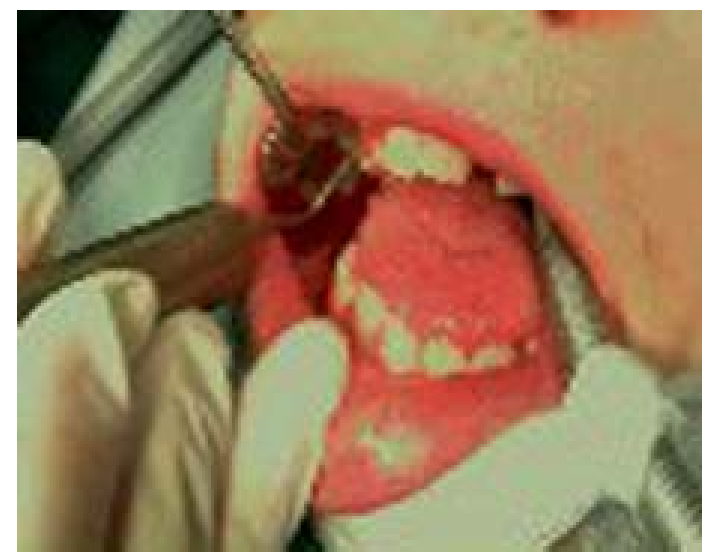

Fig. (3). Operative treatment. Professional oral hygiene.

lorism, snub nose, low-set hairline, low-set ears with flattened and slightly pointed helixes, and prominent antitragi with wide and stubby lobules (Figs. 1-2).

It was observed a severe shortened lingual frenulum leading to ankyloglossia (probable cause of the jaw's appearance), and cleft soft palate with disruption of the alveolar process. Moreover, a great amount of plaque and calculus was observed on the teeth with a severe gingivities, as well cavities on elements 16 and 36, with the following dental configuration: $16,15,14,13,12,11,21,23,64,65,26$, $36,75,74,73,32,31,41,42,43,84,85,46$ with persisting of several deciduous elements in the $2^{\text {nd }}, 3^{\text {rd }}$, and $4^{\text {th }}$ quadrants $(64,65,73,74,75,84,85)$ and agenesis of element 22.

\section{Description of Intervention}

After undergoing a cardiologic visit and being examined by anesthesiologists, the patient was admitted to Day Surgery $7.30 \mathrm{am}$. After that, the patient was intubated and 


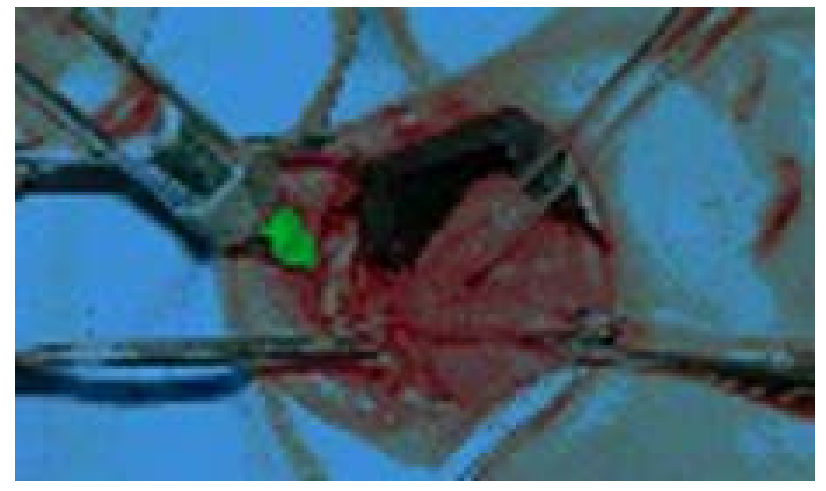

Fig. (4). Lingual Frenulectomy.

placed under anaesthesia professional oral cleaning was performed (Fig. 3). This procedure further highlighted the presence of cavities and the persistence of numerous deciduous elements in the dental arch. An intervention geared towards preserving elements 16 and 36 was conducted using reconstructive silver amalgams. Finally, a lingual frenulectomy (Fig. 4) was performed, and elements $64,65,73,74,75,84$, and 85 were removed.

\section{Release from Hospital}

After regaining consciousness without complications, the patient remained under observation as needed and was released later in the afternoon of the same day. Before the patient was released, his parents received basic instructions to be followed during the first post-surgery days (widespectrum antibiotic and anti-inflammatory treatment and food intake limited to cold liquids). A follow-up visit was set up for ten days later.

\section{DISCUSSION AND CONCLUSIONS}

To the best of the authors' knowledge this is the first report describing the oral characteristics of a rare chromosomal disorder (trisomy of chromosome 8 and monosomy of chromosome 18 mosaic). The case described is characterized by several manifestations previously reported on in the literature $e . g$. the trisomy of chromosome 18 and 2, trisomy 8 mosaicism, Jacobsen syndrome 1, such as clubfoot dimorphism of the ears, heart disease, abnormal facial features and seriously altered stomatognathic system. As described in Table
1, previously unreported features included prognathism of the macrognatic lower jaw, ankyloglossia and hypodontia that should be expression of this complex chromosomal disorder. These anomalies and dimorphisms make the clinical picture extremely complicated, rendering the case approach quite challenging both in terms of systemic concerns and oral cavity related issues.

Our experience and intervention, albeit belated, enabled us to observe a distinct improvement in the patient's oral health during the three months of follow-up visits, with an improved oral hygiene at home; moreover no new cavities were observed. Finally, the psychological impact for the parents should not be underestimated, they finally felt directly involved in maintaining their child's oral and nutritional health. This decreased his discomfort despite his serious medical condition.

Often oral health is underestimated in patients affected by serious systemic disorders; this can lead to dramatic clinical situations with regard to cavities and periodontal disease, sometimes leading to loss of teeth even in young patients.

Improving the disabled patient's oral health should instead be viewed as a right and not a privilege. In fact, disabled people have a right to a health standard comparable with that afforded to other patients.

\section{REFERENCES}

[1] Lin HY, Lin SP, Chen YJ,et al. Clinical characteristics and survival of trisomy 18 in a medical center in Taipei, 1988-2004. Am J Med Genet 2006;140A: 945-51.

[2] Nucaro AL, Cao A, Faedda A, Crisponi G. Trisomy 8 mosaicism in a patient born to a mother with 47,XXX. Am J Med Genet 2003; 119A: 85-6.

[3] Courtens W, Wauters J, Wojciechowski M,et al. A de novo subtelomeric monosomy 11q (11q24.2-qter) and trisomy 20q (20q13.3qter) in a girl with findings compatible with Jacobsen syndrome: case report and review. Clin Dysmorphol 2007; 16: 231-9.

[4] Ribeiro RR, dos Santos BM, Stuani AS, de Freitas AC, de Queiroz AM. Dental findings and dental care management in trisomy 18: case report of a 13-year-old "long-term survivor". Spec Care Dentist 2006; 26: 247-51.

[5] Moskovitz M, Brener D, Annick RR. Dental management of a child with trisomy 9 mosaicism: a case report. Pediatr Dent 2006; 28: 265-8.

[6] Tatakis DN, Milledge JT. Severe gingival recession in trisomy 18 primary dentition: a clinicopathologic case report of self-inflicted injury associated with mental retardation. J Periodontol 2000; 71: 1181-6.

Received: March 29, 2011

Revised: June 22, 2011

Accepted: June 22, 2011

(C) Spano et al.; Licensee Bentham Open.

This is an open access article licensed under the terms of the Creative Commons Attribution Non-Commercial License (http://creativecommons.org/licenses/by-nc/3.0/) which permits unrestricted, non-commercial use, distribution and reproduction in any medium, provided the work is properly cited. 